Check for updates

London, UK

Cite this as: BMJ 2020;371:m4166 http://dx.doi.org/10.1136/bmj.m4166 Published: 02 November 2020

\section{Reviving clinical pharmacology: Emma Baker}

\section{The consultant in clinical pharmacology and general medicine talks to Helen Jones about her work revitalising her specialty}

\section{Helen Jones}

Emma Baker says her many roles-including training programme director for Health Education England and clinical vice president of the British

Pharmacological Society-are a result of serendipity and the fact that she faced some obstacles early in her career.

"I was very naïve when I was young and I thought, 'I don't want to do a BSc, I just want to be a doctor,' so I didn't do a BSc and that limited my choices," she says. "I had real difficulty getting into hospital medicine and I was incensed by that, so I overcompensated."

"I eventually got a job at Salford's Hope Hospital and met Leslie Turnberg, who became president of the Royal College of Physicians and inspired me to try academic medicine. He persuaded me to do a doctorate and I fell in love with research and got hooked on being a clinical academic," Baker says. "I disadvantaged myself at the start of my career and that was the grit in the oyster, to drive me on."

Baker's current aim is to revive clinical pharmacology as a specialty. "In the 1970s, clinical pharmacology was an exciting specialty with important roles in clinical and experimental medicine and regulation," she says.

"However, it became invisible in the 1980 s with the advent of organ based medicine and integration of university departments. It started to recover in the early 2000 shen it became apparent that prescribing education was otherwise lacking." She says that we are now in "an age of enlightenment," with a return to generalism and an increasing need to improve care for people with complex conditions on multiple drugs.

Clinical pharmacology is also leading the way in specialty training, Baker says, combining clinical service with academic opportunities in education and research. As a specialty with one of the lowest rates of burnout, it can provide a blueprint for the whole workforce, she says.

Covid-19 has further demonstrated how crucial clinical pharmacology is. "Clinical pharmacologists are experts in clinical trials and can make an important contribution to trial design, working with colleagues across the NHS, particularly in terms of the focus on selecting the right population, outcome measures, and drug dose," she says.

During the first wave of covid-19 Baker worked on respiratory inpatient wards. "The best of medicine as a profession came out in team working and how well we supported each other.
"As someone working in a slightly easier environment, I greatly admire and appreciate my colleagues who work in more intensive settings," Baker says. "As the first wave subsided, I returned to business as usual, developing our new polypharmacy service and innovative online education to make sure our students don't suffer because they aren't getting so much face-to-face teaching."

Baker is course director for the BSc in clinical pharmacology at St George's, University of London, the first of its kind in the UK. It aims to fill the skills gap in the specialty.

"We have a fantastic opportunity to make a scientific course truly applied, with placements, work experience, clinical trials skills, and NHS and industry mentors, so that our students see things from both sides," Baker says. "It's a coming together of the NHS, academia, and industry so we can develop a new generation of work ready graduates who are excited about clinical pharmacology."

During her own career Baker says she has been fortunate enough to have some inspiring role models and she strives to be the same for her juniors. "I remember the things I found difficult and frustrating when I was younger-such as bad supervisors or first year lectures that were dreadful and made me fall asleep-and I'm determined not to be like that," she says.

\section{Nominated by Dipender Gill}

"Emma is a charismatic and inspiring leader, with a strong sense of responsibility for improving patient care and bringing the best out of all clinical staff, including doctors, pharmacists, nurses, and all other allied healthcare professionals.

"She has played a central role in reviving the role of clinical pharmacology as a medical speciality, and has improved unity and collaboration between clinical pharmacologists throughout the UK.

“In London, specifically, Emma has rejuvenated training opportunities for clinical pharmacologists. There is now a sense of restored pride and purpose to what was previously felt by some to be a lost and forgotten speciality."

Dipender Gill is a specialty trainee year 6 in clinical pharmacology based at St George's Hospital, London 